\title{
ACTIVITY OF EFFECTIVE ELUATE FOR RELAXATION OF MUSCLE MODELS AND REMOVAL OF CALCIUM BY MICROSOMES*
}

\author{
Masa Takauji, Hisao ABE And Torao Nagai \\ Department of Physiology, Sapporo Medical College, \\ Sapporo, Japan
}

In previous papers (NAGAI et al., 1962 ${ }^{1)}$; TAKAUJI et al., 1962'), it was reported that a protein-free effective eluate obtained by a cellulose column method inhibited the myofibrillar ATPase activity and reduced the tension of glycerol-extracted muscle fibers generated by ATP. And this fact was taken as evidence that a relaxing substance may be released or produced by microsomes. On the other hand, it was published that a remarkable relaxation of muscle models such as myosin B or myofibrils was also caused by the removal of contaminant calcium from reaction mixture with a bivalent metal-chelating

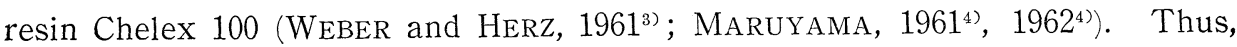
the question would be raised whether the relaxing activity of effective eluate mentioned above is due only to the removal of contaminant calcium from reaction mixture by microsomes or not.

In order to clarify this question, in the present paper, the inhibitory effect of calcium on the efficacy of effective eluate on the myofibrillar ATPase and the relaxation of muscle models in the system from which calcium was really removed by a chelating resin, were studied. The results also support the existence of a relaxing substance in the effective eluate.

\section{METHODS}

Dowex A-1 (capacity $=0.33$ mmoles of $\mathrm{Cu}\left(\mathrm{NH}_{3}\right)_{4}^{++}$par $\mathrm{ml}$ of resin) was used as chelating resin after being thoroughly washed with water, $\mathrm{HCl}, \mathrm{KOH}$ and $\mathrm{MgCl}_{2}$ in this order; this procedure was repeated several times. Before use in the assay, the resin of $\mathrm{Mg}^{++}$-form was equilibrated with cations of reaction mixture.

* A part of this work was presented by T. NAGAI at the 16th General Assembly of the Japan Medical Congress, Osaka, April 1 to 5, 1963.

The following abbreviations were used: ATP, adenosinetriphosphate; EDTA, ethylenediaminetetraacetic acid; EGTA, ethyleneglycol-bis ( $\beta$-aminoethyl)-N, $N^{\prime}$-tetraacetic acid; Tris buffer, tris (hydroxymethyl) aminometane-acetate buffer.

Received for publication June 2, 1963.

高氏 昌, 阿部久男, 永井寅男 
The determination of calcium content of reaction mixture or myofibrils was performed by YANAGISAWA's method (1955) ${ }^{5)}$ or EDTA-titration method using thymolphthalein complexone as an indicator at $\mathrm{pH}$ 11. To the measurement of contaminant calcium in $\mathrm{KCl}$ or $\mathrm{KCl}+$ oxalate solution, especially, YANAGISAWA's ultramicro determination method $(1953)^{6)}$ was applied.

Calcium depriving activity of Dowex A-1 was determined by the following two manners: firstly, $5 \mathrm{ml}$ of reaction mixture, to which $1 \cdot 10^{-3} \mathrm{M} \mathrm{CaCl}_{2}$ and 3 or $4 \mathrm{ml}$ of Dowex A-1 were added, was centrifuged and then the supernatant was analyzed for their calcium content by the EDTA-titration method; secondly, ${ }^{45} \mathrm{Ca}(2.7 \mu \mathrm{c} / \mathrm{mmole})$ was added to give a final concentration of $1 \cdot 10^{-5} \mathrm{M}$ calcium to reaction mixture. The ${ }^{45} \mathrm{Ca}$ content of the reaction mixture after passage through a Dowex A-1 column $(1 \times 13 \mathrm{~cm})$ was compared with that of the initial reaction mixture. The radioactivity of each reaction mixture was measured with a Geiger-Müller counter.

In these experiments, laboratory wares were cautiously washed with Dowex A-1treated solution before use to avoid contamination by extraneous calcium as much as possible.

Other materials and methods were the same as reported elsewhere (NAGAI and UCHIDA, 19607); NAGAI et al., 1962') ).

EDTA and EGTA were obtained from Dojin Pharmaceutical Laboratories (Kumamoto). ${ }^{45} \mathrm{CaCl}_{2}$ was purchased from Japan Radioisotope Association.

\section{RESULTS}

In our experiments, it was found that the reaction mixture was contaminated with calcium of 2.3 to $4.1 \mu \mathrm{M}$ (average of 4 experiments, $3.0 \mu \mathrm{M}$ ) and its major part was derived from $\mathrm{KCl}$, and that the calcium content of myofibrils was 2.7 to $4.8 \mu \mathrm{moles} / \mathrm{g}$ of protein (average of 6 experiments, $3.2 \mu \mathrm{moles} / \mathrm{g}$ of protein). Moreover, the concentration of free calcium contaminating $0.1 \mathrm{M}$ $\mathrm{KCl}$ solution was reduced to $2 / 3 \sim 1 / 2$ by the addition of $2 \mathrm{mM}$ oxalate.

As shown in FIG. 1, the relaxing activity of effective eluate on the myofibrillar ATPase was progressively inhibited with increased calcium concentration. The inhibition, however, was only slight at the calcium concentration $(3.0 \mu \mathrm{M})$ corresponding to that contaminating the reaction mixture. About $20 \mu \mathrm{M}$ calcium was required for the restoration of the myofibrillar ATPase activity to the $100 \%$ activity. Furthermore, the myofibrillar ATPase activity reached to $108 \%$ at $1 \cdot 10^{-4} \mathrm{M}$ calcium, at which it coincided with the ATPase activity of myofibrils obtained without effective eluate.

In FIG. 2, the ATPase activity of myofibrils obtained by the addition of calcium in respective concentration was taken as 100\%. When the inhibitory activity of EDTA on the myofibrillar ATPase was nearly equal to that of effective eluate, the EDTA effect was removed by the addition of calcium in the same manner as that of effective eluate. Furthermore, even when EDTA was added to effective eluate, the inhibition-curve by the addition of calcium was similar to that in the case of each of effective eluate or EDTA. However, all these curves reached to their maximum at the nearly same concentration of calcium, i. e. at about $1 \cdot 10^{-4} \mathrm{M}$ calcium (FIG. 2). 


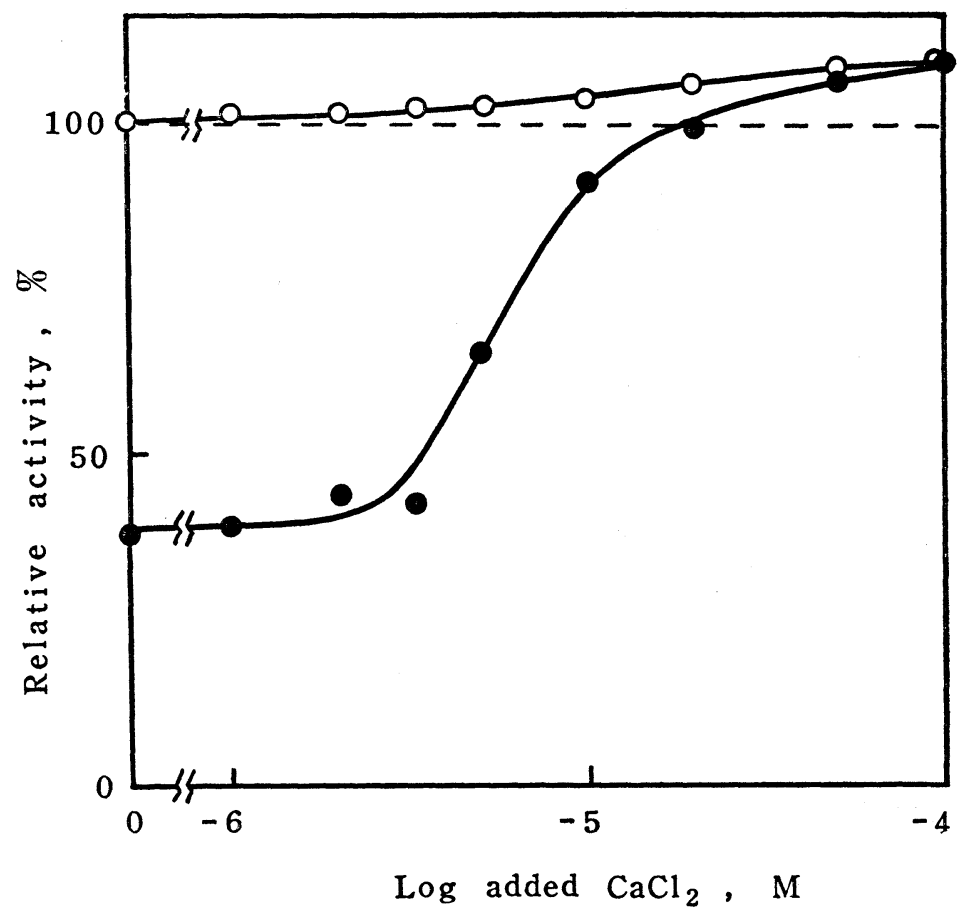

Fig. 1. Effect of calciu $n$ on the relaxing activity of effective eluate on the myofibrillar ATPase.

Ordinate: the ATPase activity of myofibrils alone obtained without added calcium was taken as $100 \%$. Abscissa : concentration of added calcium in M. Reaction mixture contained $70 \mathrm{mM} \mathrm{K}^{+}, 2 \mathrm{mM}$ ATP, $2 \mathrm{mM} \mathrm{MgCl}_{2}, 2 \mathrm{mM}$ oxalate and $70 \mathrm{mM}$ Tris acetate buffer ( $\mathrm{pH} 7.0$ ). Total volume, $2.0 \mathrm{ml}$. Myofibrils, $0.8 \mathrm{mg}$ of protein $/ \mathrm{ml}$. Temp, $20^{\circ} \mathrm{C}$. $\bigcirc$, without effective eluate;

, with effective eluate.

FIG. 3 shows that the reaction mixture pretreated with the chelating resin Dowex A-1 decreased only slightly the tension of glycerol-extracted muscle fibers generated by ATP $(6.0 \sim 8.5 \%)$. Furthermore, even by the direct addition of a large amount of Dowex A-1 $(2 \sim 4 \mathrm{ml})$ to the reaction mixture $(5 \mathrm{ml})$, the decrease in tension was only $10 \sim 20 \%$, and for reaching to this extent of decrease a longer time was required. These effects of Dowex A-1 were much less in comparison to those of effective eluate, microsomes or EDTA.

As shown in FIG. 4 the tension, which was decreased only slightly even by the direct addition of a sufficient amount of Dowex A-1, was further reduced by the subsequent addition of microsomes $(0.092 \mathrm{mg}$ of protein $/ \mathrm{ml})$, of $0.1 \mathrm{mM}$ EDTA or of $0.1 \mathrm{mM}$ EGTA; the decrease in tension was nearly the same extent as that in the presence of microsomes, EDTA or EGTA, alone. At the end of experiments, when each of the fibers was transferred to the 


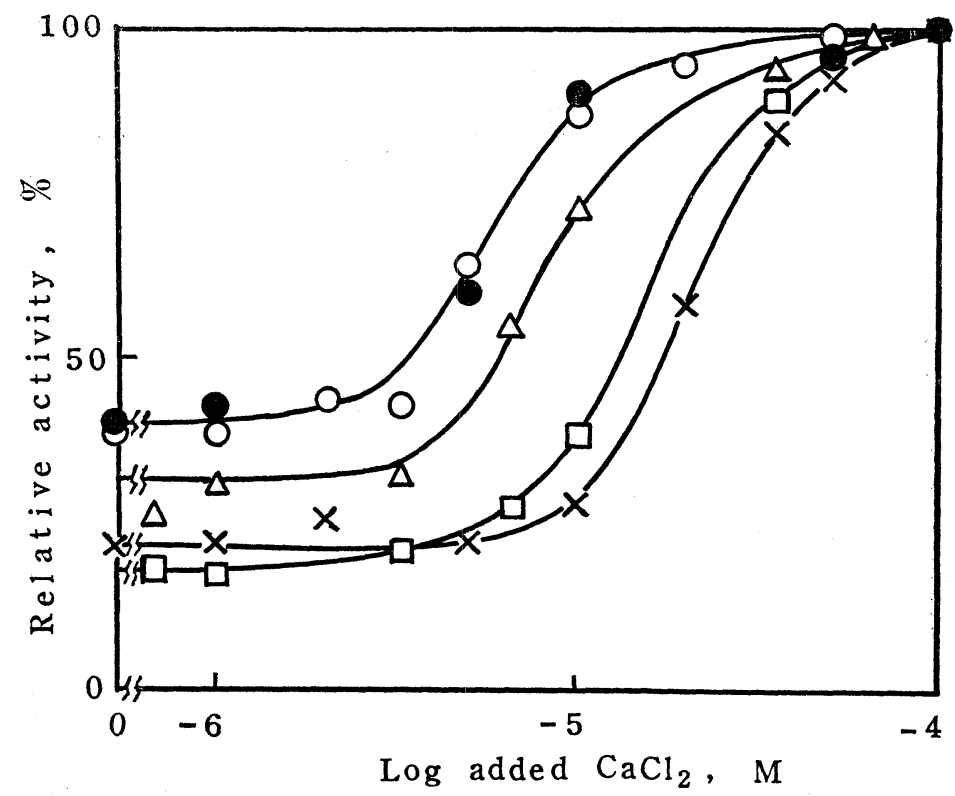

Fig. 2. Effect of calcium on the relaxing activity of effective eluate or of EDTA on the myofibrillar ATPase.

Ordinate: the ATPase activity of myofibrils obtained by the addition of calcium in respective concentration was taken as $100 \%$. $\bigcirc$, effective eluate; $0.02 \mathrm{mM}$ EDTA; $\times, 0.06 \mathrm{mM}$ EDTA; $\triangle$, effective eluate plus $0.02 \mathrm{mM}$ EDTA; $\square$, effective eluate plus $0.05 \mathrm{mM}$ EDTA. Conditions otherwise as in FIG. 1.

reaction mixture containing $2 \mathrm{mM}$ calcium, it recontracted remarkably under these conditions.

On the other hand, as shown in FIG. 5, a slight decrease in myofibrillar ATPase activity (about 10\%) was observed in the reaction mixture pretreated with Dowex A-1. The extent of this decrease was unaffected by the pretreatment of myofibrils with Dowex A-1-treated $\mathrm{KCl}$ solution. These results were different from those reported by MARUYAMA $(1961,1962)^{4}$. Furthermore, even in using Dowex A-1-treated myofibrils, the decrease in the ATPase activity was only $28 \%$. The direct addition of Dowex A-1 to the reaction mixture, however, caused a remarkable decrease of ATPase activity; when $1 \mathrm{ml}$ of Dowex A-1 was added to $1 \mathrm{ml}$ of the reaction mixture, the ATPase activity was decreased to about $30 \%$ of control. In these experiments, it was noticed that Dowex A-1 added directly to the reaction mixture affected more remarkably the myofibrillar ATPase activity than the tension of fibers (FIG. 3, 4 and 5). At present, this difference can not be completely explained, but it may be attributed to the difference in the properties of these muscle models.

In addition, it was observed that Dowex A-1 had a definite calcium depriv- 


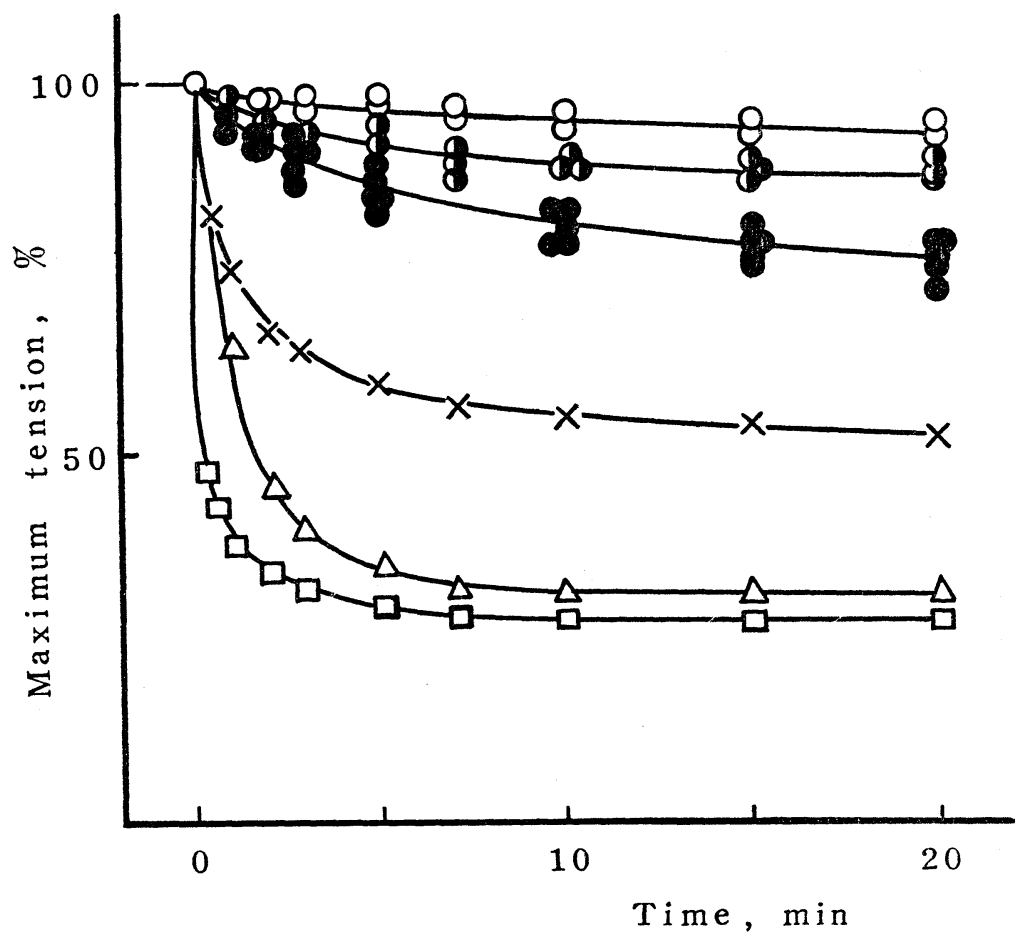

FIG. 3. Relaxation of glycerol-extracted muscle fibers induced by the reaction mixture pretreated with Dowex A-1 or by that containing $1 \sim 4 \mathrm{ml}$ of Dowex A-1, effective eluate, microsomes or EDTA.

$0,5 \mathrm{ml}$ of reaction mixture was pretreated with 1 or $3 \mathrm{ml}$ of Dowex A-1; C, $1 \mathrm{ml}$ of Dowex $\mathrm{A}-1$ was added to $5 \mathrm{ml}$ of reaction mixture;, $2 \sim 4 \mathrm{ml}$ of Dowex A-1 was added to $5 \mathrm{ml}$ of reaction mixture; $\times$, effective eluate; $\triangle$, microsomes $(0.22 \mathrm{mg}$ of protein $/ \mathrm{ml}) ; \square, 0.5 \mathrm{mM}$ EDTA. Extraction period of fibers, 8 months. Average of maximum tension, $2020 \mathrm{~g} / \mathrm{cm}^{2}$. $\mathrm{K}^{+}$, $82.4 \mathrm{mM}$; Tris acetate buffer, $66.7 \mathrm{mM}$. Conditions otherwise as in FIG. 1.

ing activity under these conditions; when 3 or $4 \mathrm{ml}$ of Dowex A-1 was added to $5 \mathrm{ml}$ of reaction mixture containing $1 \cdot 10^{-3} \mathrm{M}$ calcium, the calcium was almost completely removed from the reaction mixture ( $>0.94$ or $>0.99 \mathrm{mM}$, respectively). On the other hand, the amount of ${ }^{45} \mathrm{Ca}\left(1 \cdot 10^{-5} \mathrm{M}\right)$ added to reaction mixture decreased to $4.0 \cdot 10^{-9}$ to $7.0 \cdot 10^{-10} \mathrm{M}$ after passage through a Dowex A-1 column.

\section{DISCUSSION}

A far larger amount of calcium than that contaminating the reaction mixture was required for a sufficient restoration of myofibrillar ATPase activity inhibited by effective eluate. This result would suggest that the relaxing activity of effective eluate is not due to a simple removal of calcium from the 


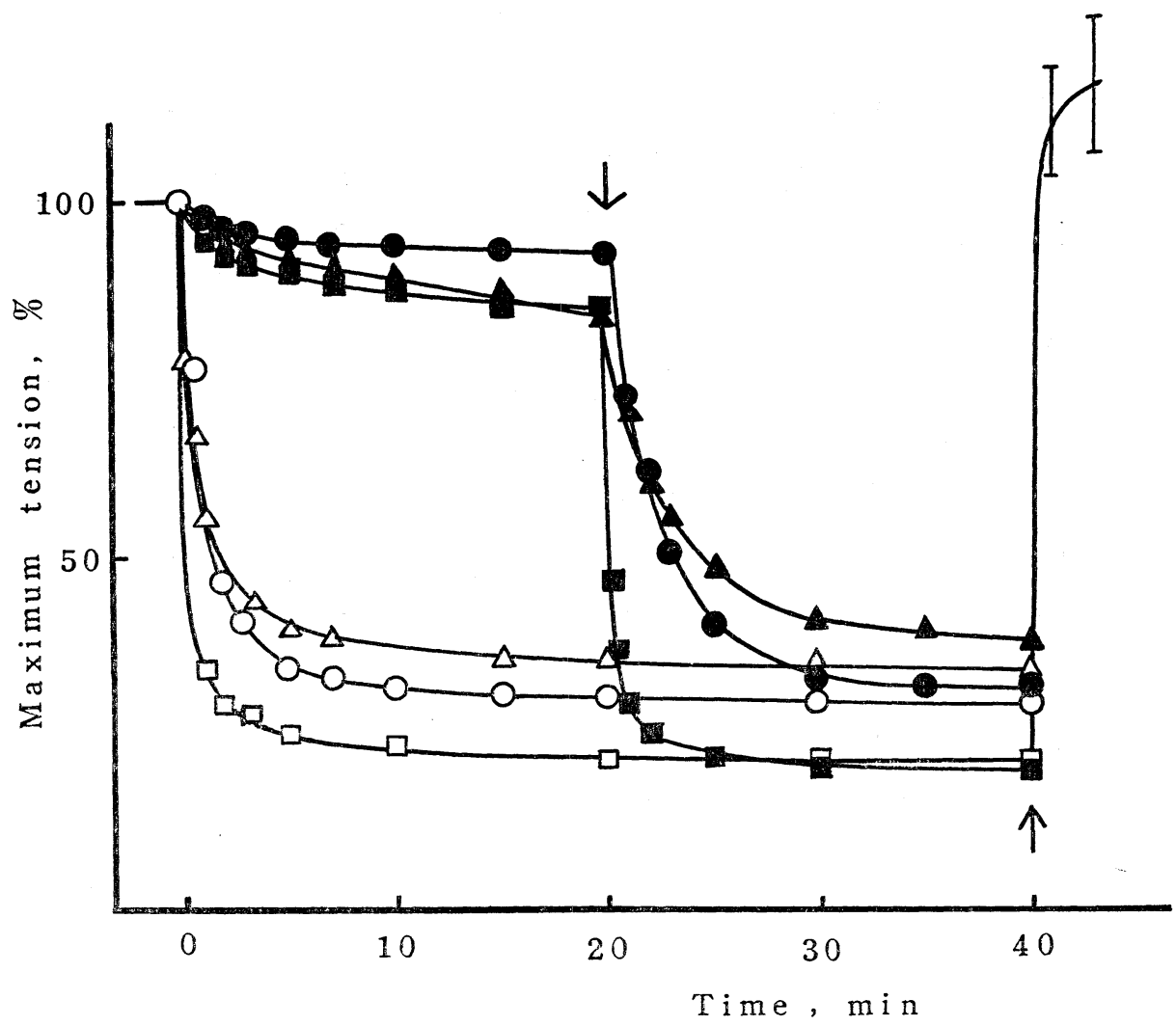

Fig. 4. Effect of microsomes, EDTA or EGTA on the tension of glycerol-extracted muscle fibers in the presence of Dowex A-1.

$4 \mathrm{ml}$ of Dowex A-1 was added to $3 \mathrm{ml}$ of reaction mixture. First arrow indicates the addition of microsomes, EDTA or EGTA, and second arrow indicates that fibers were transferred to the reaction mixture containing $2 \mathrm{mM} \mathrm{CaCl}_{2}$. $\bigcirc$, microsomes $(0.092$ $\mathrm{mg}$ of protein $/ \mathrm{ml}) ; \Delta, \mathbf{A}, 0.1 \mathrm{mM}$ EDTA; $\square$, $0.1 \mathrm{mM}$ EGTA. Open symbols, in the absence of Dowex A-1. Solid symboles, in the presence of Dowex A-1. Extraction period of fibers, 3.5 months. Average of maximum tension, $2520 \mathrm{~g} / \mathrm{cm}^{2}$. Conditions otherwise as in FIG. 3.

reaction mixture by microsomes, and that there is a relaxing substance in the effective eluate.

In addition, the decrease in myofibrillar ATPase activity or in tension of fibers was at most $10 \%$ in the reaction mixture pretreated with Dowex A-1 which could really remove free calcium. Moreover, the extent of this relaxation was at most $20 \sim 30 \%$ even after the treatment of myofibrils with Dowex A-1 (FIG. 5). And in the case of fibers, the decrease in tension was at most $20 \%$ even after the direct addition of a sufficient amount of Dowex A-1 to the reaction mixture (FIG. 3 and 4). Furthermore, microsomes could remarkably reduce the tension of fibers even in the absence of free calcium (FIG. 4). 


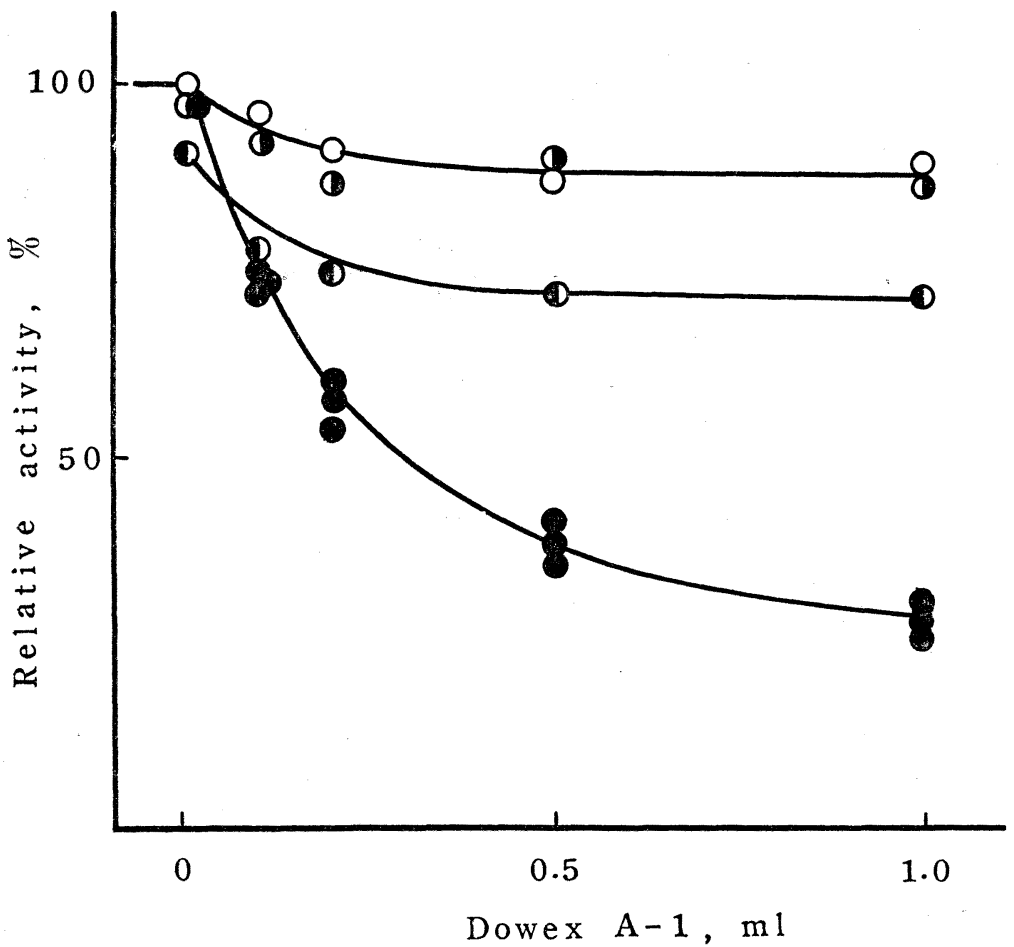

FIG. 5. Influence of the pretreatment of reaction mixture or myofibrils with Dowex A-1 on the myofibrillar ATPase activity.

Abscissa, the amounts of Dowex A-1 in ml, used for treatment of $1 \mathrm{ml}$ of the reaction mixture. Myofibrils, $0.80 \mathrm{mg}$ of protein $/ \mathrm{ml}$. $\bigcirc$, non-treated myofibrils; myofibrils were washed with $0.1 \mathrm{M} \mathrm{KCl}$ solution pretreated with Dowex A-1; C, myofibrils were pretreated with Dowex A-1; $10 \mathrm{ml}$ of myofibrils suspended in $0.1 \mathrm{M} \mathrm{KCl}$ solution were mixed with $5 \mathrm{ml}$ of Dowex A-1 for 15 min, and then the Dowex A-1 was separated from myofibrils by centrifugation. Dowex A-1 was added directly to the reaction mixture. Conditions otherwise as FIG. 1.

These results would further support the above mentioned consideration. In addition, it could be considered that the relaxing activity of microsomes is due mainly to a relaxing substance released or produced by microsomes, because the relaxing activity to be attributed to the removal of free calcium is only slight.

On the other hand, comparing the removal of EDTA effect by calcium with that in the case of effective eluate (FIG. 2), it may be considered that the relaxing substance could be a chelator with a similar property to EDTA for calcium-binding. However, the fact that all the curves in FIG. 2 reached to their maximum at about $1 \cdot 10^{-4} \mathrm{M}$ calcium in our experiment may exclude the possibility that the relaxing substance or EDTA acts through a simple chela- 
tion of free calcium, and suggest that the relaxing substance or EDTA might act directly on the contractile proteins in contrast with the view that EDTA does not directly bind to actomyosin ${ }^{4,8,9)}$. For if the relaxing substance or EDTA acted only by the removal of free calcium, these curves in FIG. 2 should be moved in parallel with the abscissa toward the right depending on the concentration of calcium added to their reaction mixture. This suggestion is further supported by the results in FIG. 4 showing that microsomes, EDTA or EGTA could cause a remarkable relaxation of the fibers, in spite of the almost complete removal of free calcium from the system by the direct addition of a sufficient amount of Dowex A-1.

\section{SUMMARY}

1. In the experiment on myofibrillar ATPase activity, the calcium at the concentration $(3.0 \mu \mathrm{M})$ corresponding to that contaminating the reaction mixture inhibited only slightly the relaxing activity of effective eluate. A far larger amount of calcium than that contaminating the reaction mixture was required for a sufficient restoration of myofibrillar ATPase activity inhibited by effective eluate.

2. The inhibition-curve of the relaxing activity of effective eluate by the addition of calcium was similar to that in the case of EDTA or EDTA plus eluate. However, all the curves reached to their maximum at about $1 \cdot 10^{-4} \mathrm{M}$ calcium.

3. The decrease in myofibrillar ATPase activity or in tension of fibers was at most $10 \%$ in the reaction mixture pretreated with Dowex A-1. The direct addition of Dowex A-1 having a sufficient binding capacity for calcium had only a slight effect on the relaxation of glycerol-extracted muscle fibers.

4. The tension of glycerol-extracted muscle fibers, even in the system from which the free calcium was almost completely removed by the direct addition of a sufficient amount of Dowex A-1, was remarkably decreased by the subsequent addition of microsomes, EDTA or EGTA.

After completion of this work, the recent paper by BRIGGS and KING (1962) ${ }^{10)}$ titled "Calcium and contraction of glycerinated muscle fibers" came to the attention of the authors. Their results are in part similar to ours.

\section{REFERENCES}

1) Nagai, T., Uchida, K. and Yasuda, M. Some further properties of the muscle relaxing-factor system and the separation of the effective substance. Biochim. Biophys. Acta 56 : 205-215, 1962.

2) Takauji, M., TAkAhashi, H. and NAGAi, T. Effect of soluble relaxing substance on glycerol-extracted muscle fiber. Biochim. Biophys. Acta 65: 531-533, 1962.

3) Weber, A. and Herz, R. Requirement for calcium in the synaeresis of myofibrils. 
Biochem. Biophys. Res. Comm. 6 : 364-368, 1961.

4) Maruyama, K. Action of relaxing agents on the actomyosin-ATP system. Zoological Magazine (Japanese text) $71: 137-142,1962$. Cited by Weber, A. and HerZ, R. Biochem. Biophys. Res. Comm. 6: 364-368, 1961.

5) YanAgisawa, F. New colorimetric determination of calcium and magnesium. $J$. Biochem. (Japan) 42: 3-11, 1955.

6) Yanagisawa, F. The determination of calcium by new method. (IX) About extraction of obstacle substance and ultramicro determination method of water hardness. Niigata Med. J. (Japan) 67:387-390, 1953.

7) NAGAI, T. and UchiDA, K. Effect of some contracture-producing agents on glycerol-extracted muscle fiber relaxed with relaxing factor. Biochim. Biophys. Acta $44: 334-340,1960$.

8) Ebashi, F. Does EDTA bind to actomyosin? J. Biochem. 50:77-78, 1961.

9) Weber, A. and Winicur, S. The role of calcium in the superprecipitation of actomyosin. J. Biol. Chem. 236 : 3198-3202, 1961.

10) BRiggs, F.N. and KING, R. Calcium and contraction of glycerinated muscle fibers. I. Removal of calcium with "granules" or a metal-binding resin. Biochim. Boiphys. Acta $65: 74-81,1962$. 